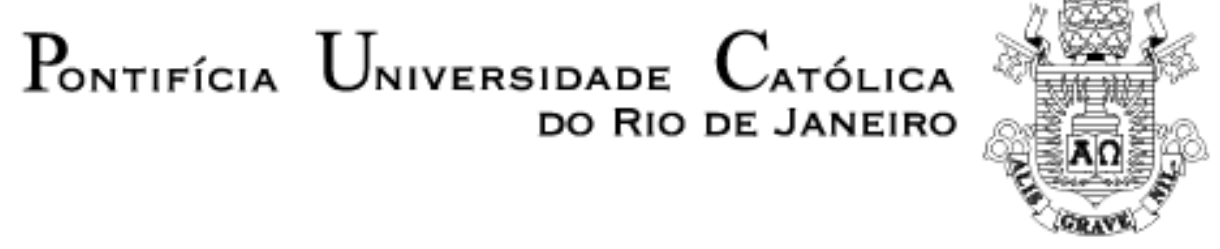

Nilton Pereira Silva

\title{
O CASAMENTO DE NELSON RODRIGUES, UMA EXPERIÊNCIA DE LEITURA E ESCRITA
}

Dissertação de Mestrado

Dissertação apresentada como requisito parcial para a obtenção do grau de Mestre pelo Programa de Pósgraduação em Literatura, Cultura e Contemporaneidade do Departamento de Letras da PUC-Rio.

Orientador: Prof. Marília Rothier Cardoso

Rio de Janeiro Abril de 2013 


\section{Pontifícia Universidade Católica $_{\text {and }}$ \\ DO RIO DE JANEIRO}

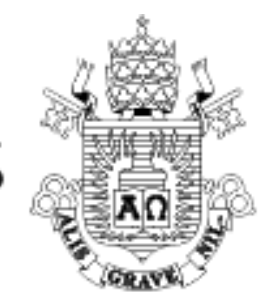

Nilton Pereira Silva

\section{O CASAMENTO DE NELSON RODRIGUES, UMA EXPERIÊNCIA DE LEITURA E ESCRITA}

Dissertação apresentada como requisito parcial para a obtenção do grau de Mestre pelo Programa de Pós-graduação em Literatura, Cultura e Contemporaneidade do Departamento de Letras do Centro de Teologia e Ciências Humanas da PUC-Rio. Aprovada pela comissão examinadora abaixo assinada.

Profa. Marília Rothier Cardoso

Orientadora

Departamento de Letras - PUC-Rio

Prof. Júlio Cesar Valladão Diniz Departamento de Letras - PUC-Rio

Profa. Pina Maria Arnoldi Coco

Profa. Denise Berruezo Portinari Coordenadora Setorial do Centro de Teologia e Ciências Humanas - PUC-Rio

Rio de Janeiro, 1 de abril de 2013. 
Todos os direitos reservados. É proibida a reprodução total ou parcial do trabalho sem a autorização da universidade, do autor e do orientador.

\section{Nilton Pereira Silva}

Atuou em monitorias de português e inglês no PET (Programa de Educação Tutorial) de Letras de 2005 a 2009. Graduou-se em Letras (licenciatura bilíngue Português/Inglês e literaturas correspondentes) na PUCRio em 2009. Participou de vários congressos na área de literatura. Ministra aulas de português aos alunos do Colégio Pedro II. É professor do ensino fundamental e do ensino médio da rede pública municipal e estadual.

\section{Ficha Catalográfica}

Silva, Nilton Pereira

O Casamento de Nelson Rodrigues, uma experiência de leitura e escrita / Nilton Pereira Silva ; orientador: Marília Rothier Cardoso. - 2013.

103 f. ; $30 \mathrm{~cm}$

Dissertação (mestrado) - Pontifícia Universidade Católica do Rio de Janeiro, Departamento de Letras, 2013.

Inclui referências bibliográficas

1. Letras - Teses. 2. Experimento narrativodramático. 3. Teatralidade. 4. Escrita. 5. Efeitos cênicos. 6. Sensações. 7. Experiência. 8. Rodrigues, Nelson. I. Cardoso, Marília Rothier. II. Pontifícia Universidade Católica do Rio de Janeiro. Departamento de Letras. III. Título. 
À minha mãe, Rosangela, por me introduzir ao Reino das Palavras

À minha avó, Maria da Aparecida, pelo incansável incentivo de admiradora

À Pina, com quem comecei esse trabalho

À Marília Rothier, pela confiança transmitida e pela confiança depositada neste projeto 


\section{Agradecimentos}

A Deus, por ter vindo comigo até aqui.

À Pina, pela ideia e pelas conversas inicias que me renderam esta pesquisa.

À Marília Rothier, pela generosidade com que acolheu meu trabalho e pela parceria construída durante a orientação.

A Júlio Diniz, por ampliar meus horizontes sobre leitura crítica.

A todos os professores e funcionários do Departamento de Letras PUC-Rio.

Ao CNPq e à PUC-Rio, pelos auxílios concedidos, sem os quais este trabalho não poderia ter sido realizado.

Aos funcionários da Biblioteca Central da PUC, da Biblioteca Euclides da Cunha, da Biblioteca Infantil do Méier e da Biblioteca do Engenho Novo, por não se cansarem de me ajudar e pela simpatia.

À minha mãe, pela grande torcida.

À minha avó, pela escuta sempre atenciosa do meu texto e pelas interessantes observações feitas em nossas discussões.

Ao meu amor, Luana, pela leitura e crítica, pela troca de ideias, pelo apoio, pelo companheirismo. E pelo carinho.

A todos que enviaram vibrações positivas para a realização deste trabalho. 


\section{Resumo}

Silva, Nilton Pereira; Cardoso, Marília Rothier. O Casamento de Nelson Rodrigues, uma experiência de leitura e escrita. Rio de Janeiro, 2013. 103p. Dissertação de Mestrado - Departamento de Letras, Pontifícia Universidade Católica do Rio de Janeiro.

Em seu romance $O$ casamento, Nelson Rodrigues desloca sua experiência na dramaturgia para os limites da literatura, levando as palavras, a partir de sua materialidade, a operar encenações na narrativa ficcional. Daí surge a noção de teatralidade caracterizadora de uma escrita de sensações com inegável vigor e impacto. Tal prática artística explora a linguagem verbal para que esta presentifique o corpo ausente dos protagonistas e arme um jogo sintático planejado para produzir movimento, ritmo, imagens visuais, táteis e sonoras. Assim, o leitor vivencia a trama durante a experiência marcante de leitura do texto. Diante disso, investiga-se a influência da teatralidade tanto na estrutura do romance como no experimento da sintaxe frasal de um tipo de texto lítero-dramático que Nelson inventa, onde o sentido ultrapassa as fronteiras da linguagem e educa a sensibilidade do corpo-leitor para experimentar a força viva dessa escrita.

\section{Palavras-chave}

Experimento narrativo-dramático; teatralidade; escrita; efeitos cênicos; sensações; experiência; Nelson Rodrigues. 


\section{Abstract}

Silva, Nilton Pereira; Cardoso, Marília Rothier (Advisor). The Wedding by Nelson Rodrigues, an experience of reading and writing. Rio de Janeiro, 2013. 103p. MSc. Dissertation - Departamento de Letras, Pontifícia Universidade Católica do Rio de Janeiro.

In his novel The Wedding, Nelson Rodrigues moves his experience in playwriting to the boundaries of literature making the words to perform dramatizations in the fictional narrative. Hence the notion of theatricality that characterizes a kind of writing of sensations with undeniable force and impact rises. Such artistic practice explores verbal language so that it is able to recover the absent body of the protagonists and set a syntactic game planned to produce movement, rhythm, visual, sound and tactile images. Thus, the reader experiences the plot during the remarkable experience of reading. Therefore, this dissertation investigates the influence of theatricality on the structure of the novel as well as the experiment of phrasal syntax of a type of literary-dramatic text that Nelson invents, in which the meaning transcends the boundaries of language and educates the sensitivity of the body-reader to experience the power of this alive writing.

\section{Keywords}

Narrative-dramatic experiment; theatrical; writing; scenic effects; feelings; experience; Nelson Rodrigues. 


\section{Sumário}

$\begin{array}{ll}\text { 1. Introdução } & 10\end{array}$

2. O experimento cênico no contorno da escrita 15

3. A teatralidade na manobra dos efeitos do experimento 32

3.1 O cruzamento da teatralidade com a ficção narrativa 32

3.2 A animação da realidade pelo teatro do verbo na construção da cena: o efeito de "vida" 53

3.3 A oralidade: o diálogo como aditivo da força de expressão da cena 73

4. Conjecturas sobre a interdição e a crítica em de $O$ Casamento 84

5. Considerações finais 96

6. Referências bibliográficas $\quad 99$ 
O engano milenar do teatro é que fez do palco um espaço exclusivo de atores e de atrizes. Por que nós, os não-atores, as não-atrizes, não teremos também o direito de representar? Objetará alguém que não dominamos o meio de expressão teatral. Protesto: dominamos, sim. Que fazemos nós, desde que nascemos, senão teatro, autêntico, válido, incoercível teatro? 